Cropley, M., Michalianou, G. Pravettoni, G,. \& Millward, L. (2012). The relation of post work ruminative thinking with eating behaviour. Stress and Health, 28, 23-30.

\title{
THE RELATION OF POST WORK RUMINATIVE THINKING WITH EATING BEHAVIOUR
}

\begin{abstract}
Inability to unwind about work during leisure time has been associated with a number of negative health outcomes. This study was concerned with a possible behavioural pathway between unwinding and disease and examined the relationship between work related rumination and food choice. Work related rumination is arguably core to understanding the 'unwinding process', and food choice is a well established indicator of nutritional health. Two hundred and ninety-eight full-time workers from a range of white collar occupations completed a self-report measure of ruminative thinking about work and an eating behaviour questionnaire. Three types of ruminative thinking were identified by factor analysis and labelled: affective rumination, problem-solving pondering and detachment respectively. In terms of food choice, high relative to low affective ruminators, reported eating more unhealthy foods, and low detachers reported eating less cooked meals and more processed foods compared to high detachers. Problem-solving pondering was not associated with food choice, and none of the factors were associated with healthy food choice. It was concluded that failure to unwind from work is not necessarily related to unhealthy food choices. What appears to be the crucial factor is the type of perseverative thinking people engage in post work. Limitations and future directions are discussed.
\end{abstract}


Perseverative thinking about work during leisure time is integral to the inability to unwind, which is in turn, associated with a number of negative health outcomes (reported below). This study looks closely at one possible behavioural pathway between unwinding and disease, examining in particular an exemplar of how work related rumination can influence food choice. Food choice is selected because of its nutritional indicator and because it is a behaviour that is well established to be stress sensitive.

It is not unusual for people to think and reflect about work-related issues when not at work, and many people do this because they find it stimulating and rewarding. For example, they may reflect on how well a particular meeting went at work, or the successful completion of a particular deal. In addition, some individuals may use their leisure time to think about interesting aspects of their job in order to find solutions to problems they have been unable to solve at work. However there are many individuals who find that they are unable to escape from their work and thinking or ruminating about work issues when not at work dominates much of their free time. For example, using items from Warr's 'work-strain' measure (Warr, 1990), The Employment of Britain Survey (1992) interviewed over 3000 workers and revealed that $70 \%$ of them found it difficult to unwind after work (Gallie, White, Cheng, \& Tomlinson, 1998). The survey also revealed that $72 \%$ of individuals at some time worry about their job after work, with $22 \%$ describing themselves as regular worriers. Moreover, $11 \%$ stated they worry about their job after work much of the time (Gallie, et al., 1998). Research also suggests that the proportion of workers who find it difficult to unwind after work and worry about their job after work is increasing (Felstead, Gallie, \& Green, 2002). It is important to have an understanding of the 'unwinding process' as inadequate recovery or poor disengagement from work is associated with an increase in saliva cortisol secretion (Rydstedt, Cropley, Devereux, \& Michalianou, 2009), and a number of health problems including: cardiovascular disease (Kivimaki, Leino-Arjas, Kaila-Kangas, 
Luukkonen, Vahtera, Elovainio et al., 2006; Suadicani, Hein, \& Gyntelberg, 1993), negative mood (Pravettoni, Cropley, Leotta, \& Bagnara, 2007), and sleep disturbance (Akerstedt, Knutsson, Westerholm, Theorell, Alfredsson, et al., 2002; Cropley, Dijk, \& Stanley, 2006; Nylen, Melin, \& Laflamme, 2007). For instance, a prospective study found that men who reported an inability to relax after work, had an approximately threefold increased risk of heart disease (Suadicani, et al., 1993). Another study showed people who experience 'persistent thoughts about work' were three times more likely to report sleep disturbance, compared to those that did not (Akerstedt, et al., 2002). The above studies suggest that it may not necessarily be work demands per se that cause health problems, but the failure to adequately unwind from work that is the critical factor in this process. It is therefore important to understand how people unwind and switch-off from work, during non paid working hours (Zijlstra \& Sonnentag, 2006).

\section{Mechanisms}

Whilst the exact mechanism underlying the association between unwinding and health is unclear, at least two distinct pathways may be involved: the physiological and the behavioural. Although not fully understood, two involuntary branches of the autonomic nervous system are thought to be closely involved in the progression from stress to illness/disease: the sympathetic nervous system, and the parasympathetic nervous system. When the body is under threat or stressed, sympathetic activity (or parasympathetic withdrawal) mobilises the organism for action by initiating physiological arousal, such as increasing blood pressure, heart-rate, catecholamine, and corticosteroid secretion. In the absence of threat or perceived stress, the parasympathetic system counteracts the effects of sympathetic activity and restores homeostasis. These two mechanisms serve to protect the organism in the short-term, but can have damaging effects if stress is prolonged. 
The effect of the stressor may be long felt even when the object causing the strain response is no longer present. For instance, a person who has a quarrel with a colleague at work may continue to think and ruminate about the encounter post work. In doing so, they may also experience the same physiological arousal that originally accompanied the stressor. A demonstration of this was shown in an interesting laboratory study by Glynn and colleagues (Glynn, Christenfeld, \& Gerin, 2007). In this study, participants were asked to perform a mental stress task but in addition were harassed while doing so. After 30 minutes following the completion of the task, they returned to the laboratory where they were asked to recall the experience. In doing so, the participants showed elevated cardiovascular responses, with increased blood pressure and heart-rate. Moreover, this effect was still present when they were tested one week later. This suggests, that the reactions to stress can be sustained over a long period of time, particularly in individuals who perseverate about the stressor (Brosschot, Gerin, \& Thayer, 2006), and persistent failure to unwind following periods of arousal is thought to be detrimental to health because it wears down the body's physiological restorative system (McEwen, 2007). Unwinding following a stressful working day is therefore necessary in order to prevent further wear on the physical organism and aid reparative function during the night.

The behavioural pathway between stress, unwinding and health can be influenced by many factors. For example leading a sedentary life style, drinking alcohol to excess, smoking, and moderating eating habits, have all been implicated in the aetiology of disease, and all may be involved in the process of unwinding and health. For example, individuals who find it difficult to unwind from work may increase their smoking and/or alcohol intake as they feel this will help them relieve the psychological consequences of stress, such as tension or anxiety (Arnetz, 1991; Cooper, Frone, Russell, \& Mudar, 1995; Steptoe, et al., 1998; Steptoe, Lipsey, \& Wardle, 1998). In a study of transit operators, Delaney and 
colleagues found that those who skipped meals also took longer to unwind from work (Delaney, Grube, Greiner, Fisher, \& Ragland, 2002).

It is widely reported that eating habits are moderated in response to stress (Gibson, 2006), although the research is equivocal: some studies find people increase their food intake in response to stress exposure (Laitinen, Ek, \& Sovio, 2002), while others find a decrease (Stone, \& Brownell, 1994). Less is known about actual food choice, however studies have reported that people will increase their energy, fat and sugar intake, when demands are particularly high (Lowe, \& Fisher, 1983; Steptoe, et al., 1998). People may modify their eating habits in order to regulate their emotions, and use eating as a maladaptive coping strategy in response to negative affect (Spoor, Bekker, Van, Strien, \& van Heck, 2007). In anticipating a stressor individuals have also been shown to have a higher tendency to use food in order to distract themselves from stress (Macht, Haupt \& Ellgring, 2005). The link between stress and affect, and food choice is complex, yet studies have found associations between negative affect and stress, and the increased consumption of high-fat and convenience 'snack' foods (Lowe, \& Fisher, 1983; Conner, Fitter, \& Fletcher, 1999; O’Conner \& O'Conner, 2004; Steptoe, et al., 1998). A recent study reported that daily hassles were associated with an increased consumption of high fat/sugar snacks, and a reduction of main meals and vegetables (O'Connor, Jones, Conner, McMillan \& Ferguson, 2008).

Dietary choice research has demonstrated that people use food to maintain emotional equilibrium (Steptoe, et al., 1998), and in times of stress, people will increase their consumption of unhealthy foods, particularly if they use food to regulate their mood (Kubiak, Vogele, Siering, Schiel, \& Weber, 2008; Macht, 2008; Steptoe, et al.,1998). Given that work strain can be considered as a prolongation of work stress, and stress at work has been associated with unhealthy eating, it is conceivable that people who fail to unwind and 
ruminate about work issues during their leisure time are more likely to adopt unhealthy eating habits. In view of the limited information on this topic, the aim of the present study was to assess the relationship between work related rumination and food choice.

\section{METHOD}

Participants and Procedure

\section{Procedure}

Individuals were selected via an opportunity sample of working adults using the snowballing method, and via contacts within organisations the researchers had previously consulted with. Those interested were then directed to a website that gave instructions and background information on how to complete the questionnaires. In total 298 responses were registered but 30 of these were not finished and were excluded from the analysis. Complete data was obtained from 268 full time employees from a wide range of white collar jobs, including: administration (12.7\%) banking finance (11.5\%), consultancy (1.\%), education (15.6\%), health (4.5\%), human resources $(2.6 \%)$, insurance $(2.6 \%)$, IT (4.5\%), marketing $(6 \%)$ retail (3.7\%), research/science (5.2\%), and others (31\%). The participants ages ranged from 19 to 63 years and the mean age was 36.7 years $(\mathrm{SD}=12.9)$. The sample consisted of $157(58.6 \%)$ females and 111 (41.4) males. The average number of hours worked per week was 41.42 (SD $=6.58)$. 
Switching-off from work has been assessed via a number of different items and measures (e.g., Cropley \& Millward Purvis, 2003; Gallie, et al., 1998; Sonnentag \& Fritz, 2007; Warr, 1990). Although diverse, the aforementioned measures have been used to assess a general tendency for thinking or ruminating about work. To gain a greater understanding of the unwinding process, a list of ruminating items about 'switching-off' from work were specifically generated and subsequently assessed for clarity, relevance and comprehensibility by the researchers and within a series of focus groups with employees working in a range of organizations. Instructions requested respondents to answer in terms of the frequency they experience such thoughts in their leisure time. The questions were said to have face validity. Next a 25 item version of the questionnaire was piloted on an independent group of 110 white collar workers (56.6\% females, age range, 22 to 64 years). The response format utilized a five-point Likert-type scale $(1=$ very seldom or never, $2=$ seldom, $3=$ sometimes, $4=$ often, $5=$ very often or always). Factor analysis was carried out on the 25 work related rumination questions within the present sample of 268 workers. Three factors emerged with Eiganvalues greater than one, together accounting for $69.51 \%$ of the variance. An oblimin rotation was performed; variables were loaded on a single factor on the basis of the highest score, and items with a loading great than 0.4 were retained. The first factor contained five items associated with the emotional experience of not being able to switch off from work related thoughts and was labelled 'Affective Rumination' (e.g., 'do you become tense when you think about work-related issues during your free time?; Are you annoyed by thinking about work-related issues when not at work?'). The second factor, related to how individuals think, ponder and reflect about work related issues when not at work, and consisted of five items (e.g., 'In my free time I find myself re-evaluating something I have done at work; 'I find solutions to work-related problems in my free time'), and was called 'Problem-solving Pondering'. The third factor related to how easily workers are able to switch-off and leave 
work behind (e.g., 'Do you find it easy to unwind after work; Do you leave work issues behind when you leave work?'), and was called Distraction. The results of the factor analysis are summarised in Table 1, and the three factors were used in the analysis of food choice.

\section{Food choice}

Information concerning food choice was measured as snack food intake and meals eaten after work. Snacking behaviour was assessed using 10 items from the food frequency questionnaire developed by Brown and colleagues (Brown, Ogden, Vogele, \& Gibson, 2008). Snack foods were considered healthy if they had some nutritional value (e.g., fresh fruit, raw vegetables and or salad), or unhealthy if they were considered energy dense foods with little nutritional value (e.g., cakes, crisps). Participants were asked to indicate 'how often you are likely to snack on the following foods after a typical days work' and items were rated on a 5 - point scale with 'very seldom or never, seldom, sometimes, often, and very often or always'. The internal consistency (Cronbach's alpha) was .72 for healthy snacking, and .78 for unhealthy snacking. Meals after work were assessed using four items: healthy meals at home, processed foods, ready meals, and takeaways. Originally it was planned to include an item about healthy meals in restaurants but piloting revealed the frequency of this item was too low to be of any reliable use. Similar items have been used in previous research (Sparks, Hedderley, \& Shepherd, 1992).

\section{Statistical analysis}

The analysis is divided into two sections. The first section reports correlations between the three rumination factors on food choice, and work hours. For this analysis, the snack food 
choice items are collapsed into two types, healthy and unhealthy foods. The second section reports the breakdown of individual snack foods and meal types. For ease of exposition, the three rumination factors are divided along their median and a comparison is made for each type of food. Preliminary data analysis revealed no significant differences between men and women in affective rumination ( 2.2 vs. $2.4, \mathrm{t}=1.60$, n.s.), problem-solving pondering ( $2.8 \mathrm{vs}$. $2.8, \mathrm{t}=0.25$, n.s. $)$, or distraction (2.2 vs. $2.4, \mathrm{t}=1.60$, n.s. $)$.

\section{RESULTS}

\section{Work related rumination and general food choice}

The correlations between, affective rumination, problem-solving pondering and detachment with healthy and unhealthy foods are presented in Table 2 . Affective rumination was significantly positively correlated with problem-solving and unhealthy foods, but was negatively correlated to detachment. Thus, people who show emotional reactions when thinking about work related issues in their leisure time also reported eating more unhealthy foods. Problem-solving pondering was negatively correlated with detachment but did not correlate to either healthy or unhealthy food choice. Detachment was negatively correlated with unhealthy food, which suggests that those who are able to switch-off from work, eat less unhealthy foods. There was no correlation between healthy and unhealthy food choice.

\section{INSERT TABLE 1 ABOUT HERE}

Work related rumination and specific food choice 
The distribution of the snack foods was nonnormal and the analysis was conducted using nonparametric tests (Mann-Whitney). For this analysis each rumination factor was divided at the median and each food item was examined individually. Due to the number of tests performed the alpha level was set at 0.01 . The results of this analysis are presented in Table 3. High, relative to low affective ruminators reported eating more cakes, crisps, confectionery, and sweet biscuits, but there was no significant difference in the number of healthy foods consumed. High affective ruminators also reported eating more processed foods and ready meals, compared to low ruminators, and high ruminators also consumed less cooked meals. There was no significant difference in the eating habits between the high or low problem-solving pondering factor, nor was there a significant difference between high and low detachers on snack eating. There was however a significant difference in the consumption of meals, with the low detachers eating more processed foods and less cooked meals relative to the high detachers.

INSERT TABLE 2 ABOUT HERE

\section{DISCUSSION}

Failure to successfully unwind after work has been associated with a number of negative health consequences, and the aim of the present study was to assess relations of post work rumination with food choice. Factor analysis identified three different types of perseverative or ruminative thinking that people may experience following work, and these were labelled: affective rumination, problem-solving pondering and detachment.

The 'affective rumination' factor can be conceptualised as a cognitive state characterised by the appearance of intrusive, pervasive, recurrent thoughts, about work, which are negative in affective terms (Pravettoni, et al., 2007). Problem-solving pondering appears to assess the 
type of thinking people engage in about work issues when not at work because they find the act of thinking about work issues interesting. For example people may like to re-evaluate something they have done at work, or find a solution to work-related problem. This factor has similar characteristics to the 'reflective pondering' component of the Response Styles Questionnaire (RSQ; Nolen-Hoeksema \& Morrow, 1991). And finally, the third factor identified was labelled 'detachment'. Etzion and colleagues define detachment as "the individual's sense of being away from the work situation" (Etzion, Eden, \& Lapidot, 1998, p. 579). Detachment appears to assess how easy workers are able to switch-off and leave work behind and it appears that some people are able to 'switch-off' and unwind quite easily from work, but just exactly how they do this needs to be determined (Cropley \& Millward, 2009).

The three factors were moderately correlated and both affective rumination and detachment were associated with food choice. Problem-solving pondering was not associated with healthy or unhealthy eating, in terms of snack foods or types of meals consumed. High affective ruminators were found to eat more unhealthy foods relative to low affective ruminators. There was no significant difference in healthy foods. These results are broadly inline with previous literature showing an association between stress and food choice (Gibson, 2006), but they also suggest that the link between work stress and food choice may be mediated in part, by whether individuals can switch-off from work post work. In a recent study, O'Connor and colleagues, reported that increased snacking was associated with egothreatening, interpersonal and work-related hassles, whereas, physical stressors showed the opposite effect. It would be of interest for future research to examine the association between work-related rumination and ego-threatening hassles and food choice. It is likely that worker's who have a tendency to ruminate, would increase ruminating, particularly when exposed to ego-threatening stressors at work. 
Previous research has also shown detachment from work to be associated with positive well-being and low fatigue (Sonnentag, \& Bayer, 2005; Sonnentag, Mojza, Binnewies \& Scholl, 2008), and the present study showed that detachment is also associated with eating behaviour. Although there was no difference between high and low detachers in the type of snack foods consumed, low detachers reported eating less cooked meals and more processed foods relative to high detachers. Conversely, this implies that high detachers, those who easily switch-off from work, eat fewer process foods, less ready meals, and more cooked meals, and it could be argued that the process of actually cooking a meal also aids the unwinding process by diverting attention away from work related thoughts. Unfortunately we did not specify whether a cooked meal is healthy or unhealthy, but clearly processed foods can be considered the less healthy option. Also it may make a difference whether respondents eat alone or not and whether they have young children for whom they may have to cook for.

It may be argued that workers who are able to switch-off from work are likely to lead a healthy work-life balance. It is conceivable that such workers strive to control other areas of life to safeguard their health. Recently Cropley and Millward (2009) examined the process of unwinding from work and conducted interviews with workers who habitually find it difficult to switch-off from work (i.e., high ruminators), and workers who find it easy to switch-off from work (i.e., low ruminators). Interestingly, both groups readily acknowledged the benefits of leading a healthy lifestyle, yet only those who were able to detach themselves from work, i.e., the low ruminators, were able to do so. The interface between work, home and unwinding are clearly linked (Nylen, et al., 2007). A poor work-life balance has been associated with poor health (Winter, et al., 2006; Nylen, et al., 2007), which is mediated in part, by health related behaviours, e.g., lack of physical activity, increased alcohol consumption and poor dietary choices (Roos, Lahelma, \& Rahkonen, 2006; Roos, SarlioLahteenkorva, Lallukka, \& Lahelma, 2007). Improving the balance between work and home 
life has been put forward as a possible route to positive general health and well-being (Roos, et al., 2006; Roos, et al., 2007; Winter, et al., 2006).

Although the three work-related rumination factors were related and had some shared variance, what is evident from the data is that there are important distinctions between the three types of unwinding. Affective rumination was differentiated from problem-solving pondering and detachment and was uniquely associated with food choice. In short, being unable to switch-off from work did not appear to greatly influence the types of foods people ate during their free time; crucially what appeared to be the significant factor for some people, is whether or not they were able to emotionally detach from work related thoughts.

The cross-sectional nature of this study however does not allow causal inferences to be made. Our interpretation of the results is that workers, who ruminate, eat unhealthier snack foods, either to distract themselves from their thoughts or to regulate their emotions, although, it is conceivable, but not likely, the reverse is possible. Therefore the results remain tentative until the direction of causality between rumination and eating behaviour can be discerned. The use of self-report measures in this study reflects another limitation, as it is possible that some people may not accurately report their food intake. It is conceivable that some people under report their consumption of unhealthy foods, in order to portray themselves in a positive light. Finally, previous research has also found that restrained and emotional eaters are more susceptible to increase their food intake under threat or stress (O’Connor, Jones, Conner, McMillan, \& Ferguson, 2008; O’Connor \& O’Connor, 2004; Oliver, Huon, Zadro, \& Williams, 2001), and dietary status was not controlled in the present study. It would be informative to examine the association between stress, work-related rumination, food choice and dietary status in future research.

The merits of unwinding and recovering from the demands associated with work have been advocated by many researchers (Brosschot et al., 2006; Eden, 2001; Lundberg \& 
Lindfors, 2002; McEwen, 2007; Meijman \& Mulder, 1998; Zijlstra \& Sonnentag, 2006), and previous research has shown that psychological detachment from work is important for maintaining health and well-being (Cropley et al., 2006; Cropley \& Millward Purvis, 2003; Sonnentag, 2003; Sonnentag \& Bayer, 2005). Our findings are inline with previous research on recovery, in demonstrating an association between unwinding and health. Moreover, the present findings also suggests a possible behavioural mechanism for why unwinding is associated with poor health. An inability to unwind from work has been shown to be associated with an increase risk of heart disease and cardiovascular mortality (Kivimaki et al., 2006; Suadicani, et al., 1993). Eating high fat foods contributes to the development of atherosclerosis, and ruminating about work issues was associated with an increase in unhealthy eating. It will be of interest to look at whether the inability to detach oneself from work is associated with other behavioural factors known to be related to heart disease, for example, leading a sedentary lifestyle, smoking and alcohol intake.

Future research should also examine the association of rumination with objective health indices, like physical symptoms, cortisol secretion or blood pressure. Another limitation to the study was that the measure was only tested with white collar workers, albeit within a range of occupations. However, arguably the important issue is whether people ruminate or not, or the degree to which they ruminate, not what job they are doing. Previous research for example, has found that even within the same occupation, people vary in terms of how easily they switch-off from work (Cropley \& Millward Purvis, 2003). Nevertheless future research is needed to test the generalisability of the measure over different types of occupations.

Finally, future research should also examine in more detail the psychometric properties of the measure in terms of the discriminant validity of the factors against different rumination scales, e.g., the Stress-Reactive Rumination Scale (Alloy, Abramson, Hogan, Whitehouse, Rose, et al., 2000), the Response Styles Questionnaire (Nolen-Hoeksema, \& 
Morrow, 1991), and recovery measures, e.g., (Sonnentag, \& Fritz, 2007). Finally, it will be important to assess the test-retest reliability of the ruminative thinking measure.

In conclusion, the key empirical contribution of this study is in finding that the inability to switch off is not necessarily associated with unhealthy food choice: what matters is whether rumination is also coupled with an emotional reaction. Those who have a strong tendency to 'affectively ruminate' are more likely to also report eating more unhealthy foods. The indicator of affective rumination used in the current study, could be usefully employed to further explore the association between post-work cognitive perseveration that is emotionally loaded and nutritional health. 


\section{REFERENCES}

Akerstedt, T., Knutsson, A., Westerholm, P., Theorell, T., Alfredsson, L., \& Kecklund, G. (2002). Sleep disturbances, work stress and work hours: a cross-sectional study. Journal of Psychosomatic Research, 53, 741-748.

Alloy, L. B., Abramson, L. Y., Hogan, M. E., Whitehouse, W. G., Rose, D. T., Robinson, M. S., Kim, R. S., \& Lapkin, J. B. (2000). The Temple-Wisconsin Cognitive Vulnerability to Depression Project: lifetime history of axis I psychopathology in individuals at high and low cognitive risk for depression. Journal of Abnormal Psychology, 109, 403-418.

Arnetz, B. (1991). White collar stress: what studies of physicians can teach us. Psychotherapy and Psychosomatics, 55, 2-4.

Brosschot, J. F., Gerin, W., \& Thayer, J. F. (2006). The perseverative cognition hypothesis: A review of worry, prolonged stress-related physiological activation, and health. Journal of Psychosomatic Research, 60, 113-124.

Brown, K. A., Ogden, J., Vogele, C., \& Gibson, E. L. (2008). The role of parental control practices in explaining children's diet and BMI. Appetite, 50, 252-259.

Conner, M., Fitter, M., \& Fletcher, W. (1999). Stress and snacking: A diary study of daily hassles and between-meal snacking, Psychology \& Health, 14, 51-63.

Cooper, M. L., Frone, M. R., Russell, M., \& Mudar, P. (1995). Drinking to regulate positive and negative emotions: a motivational model of alcohol use. Journal of Personality and Social Psychology, 69, 990-1005.

Cropley, M., Dijk, D. J., \& Stanley, N. (2006). Job strain, work rumination, and sleep in school teachers. European Journal of Work and Organizational Psychology, 15, 181196.

Cropley, M. \& Millward Purvis, L. J. (2003). Job Strain And Rumination About Work 
Issues During Leisure Time: A Diary Study. European Journal of Work and Organizational Psychology, 12, 195-207.

Cropley, M. \& Millward, L.J. (in press). How do individuals 'switch-off' from work during leisure? A qualitative description of the unwinding process in high and low ruminators. Leisure Studies.

Delaney, W. P., Grube, J. W., Greiner, B., Fisher, J. M., \& Ragland, D. R. (2002). Job stress, unwinding and drinking in transit operators. Journal of Studies on Alcohol, 63, 420-429.

Eden, D. (2001). Vacations and other respites: Studying stress on and off the job. In C. L. Cooper \& I. T. Robertson (Eds.), International review of industrial and organizational psychology (pp. 121-146). Chichester, UK: Wiley.

Etzion, D., Eden, D., \& Lapidot, Y. (1998). Relief from job stressors and burnout: Reserve service as a respite. Journal of Applied Psychology, 83, 577-585.

Felstead, A., Gallie, D., \& Green, F. (2002). Work skills in Britain 1986-2001. Nottingham: DfES Publications.

Gallie, D., White, M., Cheng, Y., \& Tomlinson, M. (1998). Restructuring the employment relationship. Oxford: Clarendon Press.

Gibson, E. L. (2006). Emotional influences on food choice: sensory, physiological and psychological pathways. Physiology \& Behavior, 89, 53-61.

Glynn, L. M., Christenfeld, N., \& Gerin, W. (2007). Recreating cardiovascular responses with rumination: The effects of a delay between harassment and its recall. International Journal of Psychophysiology, 66, 135-140.

Kivimaki, M., Leino-Arjas, P., Kaila-Kangas, L., Luukkonen, R., Vahtera, J., Elovainio, M., Harma, M., \& Kirjonen, J. (2006). Is incomplete recovery from work a risk marker of cardiovascular death? Prospective evidence from industrial employees. 
Psychosomatic Medicine, 68, 402-407.

Kubiak, T., Vogele, C., Siering, M., Schiel, R., \& Weber, H. (2008). Daily hassles and emotional eating in obese adolescents under restricted dietary conditions - The role of ruminative thinking. Appetite, 51, 206-209.

Laitinen, J., Ek, E., \& Sovio, U. (2002). Stress-related eating and drinking behavior and body mass index and predictors of this behavior. Preventive Medicine, 34, 29-39.

Lowe, M. R., \& Fisher, E. B. (1983). Emotional Reactivity, Emotional Eating, and Obesity A Naturalistic Study. Journal of Behavioral Medicine, 6, 135-149.

Lundberg, U., \& Lindfors, P. (2002) Psychophysiological reactions to telework in female and male white-collar workers. Journal of Occupational Health Psychology, 7, 354364.

Macht, M., Haupt, C., \& Ellgring, H. (2005). The perceived function of eating is changed during examination stress: a field study. Eating Behaviors, 6, 109-112.

Macht, M. (2008). How emotions affect eating: A five-way model. Appetite, 50, 1-11.

McEwen, B. S. (2007). Physiology and neurobiology of stress and adaptation: central role of the brain. Physiological Reviews, 87, 873-904.

Meijman, T.F., \& Mulder, G. (1998). Psychological aspects of workload. In P.J.D. Drenth, H. Thierry, \& C.J. de Wolff (Eds.), Handbook of work and organizational psychology: Vol. 2 Work Psychology (pp.5-33). Hove: Psychology Press.

Nolen-Hoeksema, S., \& Morrow, J. (1991). A prospective study of depression and posttraumatic stress symptoms after a natural disaster: the 1989 Loma Prieta Earthquake. Journal of Personality and Social Psychology, 61, 115-121.

Nylen, L., Melin, B., \& Laflamme, L. (2007). Interference between work and outsidework demands relative to health: unwinding possibilities among full-time and parttime employees. International Journal of Behavioral Medicine, 14, 229-236. 
O'Connor, D.B., Jones, F., Conner, M., McMillan, B., \& Ferguson, E. (2008). Effects of daily hassles and eating style on eating behavior. Health Psychology, 27, S20-S31.

O'Connor, D.B., \& O'Connor, R.C. (2004). Perceived changes in food intake in response to stress: the role of conscientiousness. Stress and Health, 20, 279-291.

Oliver, K. G., Huon, G. F., Zadro, L., \& Williams, K. D. (2001). The role of interpersonal stress in overeating among high and low disinhibitors. Eating Behaviors, 2, 19-26.

Pravettoni, G., Cropley, M., Leotta, S. N., \& Bagnara, S. (2007). The differential role of mental rumination among industrial and knowledge workers. Ergonomics, 50, 19311940.

Roos, E., Lahelma, E., \& Rahkonen, O. (2006). Work-family conflicts and drinking behaviours among employed women and men. Drug and Alcohol Dependence, 83, 4956.

Roos, E., Sarlio-Lahteenkorva, S., Lallukka, T., \& Lahelma, E. (2007). Associations of work-family conflicts with food habits and physical activity. Public Health Nutrition, $10,222-229$.

Rydstedt, L.W., Cropley, M., Devereux, J.J., \& Michalianou, G. (2009). The Effects of Gender, Long-Term Need for Recovery and Trait Inhibition-Rumination on Morning and Evening Saliva Cortisol Secretion. Anxiety, Stress, \& Coping, 22, 465-474.

Sonnentag, S. (2003). Recovery, work engagement, and proactive behavior: A new look at the interface between nonwork and work. Journal of Applied Psychology, 88, 518- 528.

Sonnentag, S., \& Bayer, U. V. (2005). Switching off mentally: predictors and consequences of psychological detachment from work during off-job time. Journal of Occupational Health Psychology, 10, 393-414.

Sonnentag, S., \& Fritz, C. (2007). The Recovery Experience Questionnaire: development and validation of a measure for assessing recuperation and unwinding from work. 
Journal of Occupational Health Psychology, 12, 204-221.

Sonnentag, S., Mojza, E.J., Binnewies, C., \& Scholl, A. (2008). Being engaged at work and detached at home: A week-level study on work engagement, psychological detachment, and affect. Work and Stress, 22, 257-276.

Sparks, P., Hedderley, D., \& Shepherd, R. (1992). An investigation into the relationship between perceived control, attitude variability and the consumption of two common foods. European Journal of Social Psychology, 22, 55-71.

Spoor, S. T., Bekker, M. H., Van, S. T., \& van Heck, G. L. (2007). Relations between negative affect, coping, and emotional eating. Appetite, 48, 368-376.

Steptoe, A., Lipsey, Z., \& Wardle, J. (1998). Stress, hassles and variations in alcohol consumption, food choice and physical exercise: A diary study. British Journal of Health Psychology, 3, 51-63.

Steptoe, A., Wardle, J., Lipsey, Z., Mills, R., Oliver, G., Jarvis, M., \& Kirschbaum, C. (1998). A longitudinal study of work load and variations in psychological well-being, cortisol, smoking, and alcohol consumption. Annals of Behavioural Medicine, 20, 8491.

Stone, A. A., \& Brownell, K. D. (1994). The stress-eating paradox: multiple daily measurements in adult males and females. Psychology \& Health, 9, 425-436.

Suadicani, P., Hein, H. O., \& Gyntelberg, F. (1993). Are Social Inequalities As Associated with the Risk of Ischemic-Heart-Disease A Result of Psychosocial WorkingConditions. Atherosclerosis, 101, 165-175.

Warr, P. (1990). The Measurement of Well-Being and Other Aspects of Mental-Health. Journal of Occupational Psychology, 63, 193-210.

Winter, T., Roos, E., Rahkonen, O., Martikainen, P., \& Lahelma, E. (2006). Work-family conflicts and self-rated health among middle-aged municipal employees in Finland. 
International Journal of Behavioral Medicine, 13, 276-285.

Zijlstra, F.R.H., \& Sonnentag, S. (2006). After work is done: Psychological perspectives on recovery from work. European Journal of Work and Organizational Psychology, $15,129-138$. 
Table 1 Factor analyses of work-related rumination items: brief item descriptions and factor loading 
Factor $1 \quad$ Factor $2 \quad$ Factor 3

\section{Affective Rumination}

6.1 Do you become tense when you think about work-

6.10 Are you annoyed by thinking about work-related

6.20 Do you become fatigued by thinking about work-

6.24 Are you troubled by work-related issues when not

\section{Problem-Solving Rumination}

6.2 After work I tend to think of how I can improve my

6.6 In my free time I find myself re-evaluating

\section{Detachment}

6.3 Do you feel unable to switch off from work?

$6.9 \mathrm{I}$ am able to stop thinking about work-related issues

6.16 I make myself switch off from work as soon as I

6.21 Do you leave work issues behind when you leave 
Table 2. Inter correlations of the three rumination factors and healthy and unhealthy food 


\begin{tabular}{|c|c|c|c|c|c|}
\hline & $\begin{array}{c}\text { Affective } \\
\text { Rumination }\end{array}$ & $\begin{array}{c}\text { Problem- } \\
\text { Solving } \\
\text { pondering }\end{array}$ & Detachment & $\begin{array}{c}\text { Healthy } \\
\text { Foods }\end{array}$ & $\begin{array}{c}\text { Unhealthy } \\
\text { Foods }\end{array}$ \\
\hline $\begin{array}{c}\text { Affective } \\
\text { Rumination }\end{array}$ & - & & & & \\
\hline $\begin{array}{c}\text { Problem- Solving } \\
\text { pondering }\end{array}$ & $.61^{* *}$ & - & & & \\
\hline Detachment & $-.63^{* *}$ & $-.51^{* *}$ & - & & \\
\hline Healthy Foods & -.00 & .08 & .00 & - & \\
\hline Unhealthy Foods & $.26^{* *}$ & .12 & $-.18^{* *}$ & -.00 & \\
\hline
\end{tabular}

$* * p<0.001$ 
Table 3. Comparison of food items by high/low groupings 


\begin{tabular}{|c|c|c|c|c|c|c|c|c|c|c|}
\hline & & \multicolumn{9}{|c|}{ Group } \\
\hline \multirow[t]{2}{*}{ Types of food } & & \multicolumn{3}{|c|}{ Affective } & \multicolumn{3}{|c|}{$\begin{array}{l}\text { Problem-solving } \\
\text { pondering }\end{array}$} & \multicolumn{3}{|c|}{ Detachment } \\
\hline & & $\begin{array}{l}\mathrm{M} / \mathrm{M} \\
\text { Rank }\end{array}$ & $\mathrm{U}$ & $\mathrm{P}$ & $\begin{array}{l}\mathrm{M} / \mathrm{M} \\
\text { Rank }\end{array}$ & $\mathrm{U}$ & $\mathrm{P}$ & $\begin{array}{l}\mathrm{M} / \mathrm{M} \\
\text { Rank }\end{array}$ & $\mathrm{U}$ & $\mathrm{P}$ \\
\hline \multirow[t]{2}{*}{ Cakes } & Low & 120.92 & 7077. & .001 & 135.95 & 8647. & ns & 137.17 & 8595 & ns \\
\hline & High & 149.14 & & & 133.39 & & & 131.63 & & \\
\hline \multirow[t]{2}{*}{ Cereal bars } & Low & 129.73 & 8302. & ns & 127.71 & 8028. & ns & 140.56 & 8122. & ns \\
\hline & High & 139.64 & & & 139.68 & & & 127.97 & & \\
\hline \multirow[t]{2}{*}{ Chips } & Low & 123.68 & 7461. & ns & 128.50 & 8120. & $\mathrm{~ns}$ & 142.61 & 7838. & ns \\
\hline & High & 146.16 & & & 139.08 & & & 125.76 & & \\
\hline \multirow[t]{2}{*}{ Crisps } & Low & 128.69 & 8158. & .001 & 137.81 & 8432. & $\mathrm{~ns}$ & 141.77 & 7954. & $\mathrm{~ns}$ \\
\hline & High & 140.76 & & & 131.98 & & & 126.66 & & \\
\hline \multirow[t]{2}{*}{ Confectionery } & Low & 117.10 & 6546. & .001 & 133.06 & 8649. & ns & 141.29 & 8021. & ns \\
\hline & High & 153.25 & & & 135.60 & & & 127.18 & & \\
\hline \multirow[t]{2}{*}{ Dried fruit } & Low & 133.53 & 8831. & ns & 127.24 & 7974. & ns & 137.94 & 8487. & ns \\
\hline & High & 135.54 & & & 140.04 & & & 130.79 & & \\
\hline \multirow[t]{2}{*}{ Fresh fruit } & Low & 140.81 & 8089. & ns & 133.91 & 8747. & ns & 132.67 & 8710. & ns \\
\hline & High & 127.71 & & & 134.95 & & & 136.48 & & \\
\hline \multirow[t]{2}{*}{ Raw vegetables } & Low & 135.26 & 8860. & ns & 131.56 & 8647. & ns & 137.95 & 8485. & ns \\
\hline & High & 133.68 & & & 136.74 & & & 130.78 & & \\
\hline \multirow[t]{2}{*}{ Rice cakes } & Low & 134.51 & 8963. & ns & 135.42 & 8709. & ns & 133.97 & 8892. & ns \\
\hline & High & 134.48 & & & 133.80 & & & 135.07 & & \\
\hline \multirow[t]{2}{*}{ Sweet biscuits } & Low & 117.00 & 6532. & .001 & 134.42 & 8806. & ns & 140.47 & 8135. & ns \\
\hline & High & 153.36 & & & 134.56 & & & 128.07 & & \\
\hline \multicolumn{11}{|l|}{ Types of Meals } \\
\hline \multirow[t]{2}{*}{ Cooked meals } & Low & 154.54 & 6180. & .001 & 138.18 & 8389. & $\mathrm{~ns}$ & 117.77 & 6640. & .001 \\
\hline & High & 112.91 & & & 131.69 & & & 152.52 & & \\
\hline \multirow[t]{2}{*}{ Processed foods } & Low & 116.99 & 6532. & .001 & 128.04 & 8066. & $\mathrm{~ns}$ & 144.91 & 7519. & .005 \\
\hline & High & 153.36 & & & 139.43 & & & 123.29 & & \\
\hline \multirow[t]{2}{*}{ Ready meals } & Low & 116.31 & 6436. & .001 & 129.38 & 8222. & $\mathrm{~ns}$ & 141.92 & 7934. & .05 \\
\hline & High & 154.10 & & & 138.40 & & & 126.50 & & \\
\hline \multirow[t]{2}{*}{ Takeaways } & Low & 131.49 & 8546. & ns & 139.77 & 8205. & ns & 132.72 & 8717. & ns \\
\hline & High & 137.75 & & & 130.48 & & & 136.42 & & \\
\hline
\end{tabular}

